Interview

\title{
Context and Theorizing in the Global South: Challenges and Opportunities for an International Dialogue
}

Interviewee Güliz Ger ${ }^{1,2}$

Interviewers Maribel Carvalho Suare $z^{3}$ Thaysa Costa do Nascimento ${ }^{3}$

${ }^{1}$ Bilkent University, Ankara, Turkey ${ }^{2}$ University of Southern Denmark, Denmark ${ }^{3}$ Universidade Federal do Rio de Janeiro, Rio de Janeiro, RJ, Brazil

Received 27 May 2019. This document was with the authors for one revision. Accepted 25 June 2019. First published online 15 August 2019.

Marcelo de Souza Bispo was the associate editor for this document.

Editorial assistant: Luciane Kato Kiwara

Editor-in-chief: Carlo Gabriel Porto Bellini 
Brazilian researchers have been encouraged to internationalize their research, expanding their insertions into high impact international journals. This task in turn demands thinking outside the commonly used Eurocentric prism. How can Brazilian scholars say something that would be of interest globally and have an impact on the work done in the global North? How should the researcher from the global South deal with context in the international dialogue to avoid being perceived as the exotic Other? This interview with professor Guliz Ger addresses these and other important issues related to the challenge of theorizing and publishing research from a global perspective. Professor Ger's work inspires Brazilian researchers in their internationalization efforts by offering concrete examples of how to theorize, strategies to overcome editors' and journals' prejudices and convince the international audience of the value of global South, and more particularly, Brazilian research. Professor Ger's experience as a visiting professor in numerous universities around the world including in Brazil, and her service on a number of journal editorial boards, including the Journal of Consumer Research, for which she served as Associate Editor, provided the background for this interview produced by Maribel Suarez and Thaysa Nascimento.

Maribel and Thaysa: What is the relevance of contexts in the construction of theory?

Güliz: Contexts are fertile and germane to the interrelated processes of generating research questions and conceptualizing the findings. The iterative interpretive spiral of theory-data (or, data-theory) rests as much in our ability to use our theoretical toolbox as our skill to use our context. The researcher, equipped with a perspective attained from the literature, can potentially notice puzzles, anomalies, or paradoxes while observing real-world phenomena or occurrences in their natural settings - in their contexts. A focus on what is not explained in a particular context by existing theories, conventional conceptualizations, or conventional wisdom in turn stimulates new research projects, discoveries, and/or problematizations (Alvesson \& Sandberg, 2011) of the extant literature; and thus potential theory development and interesting contributions (Davis, 1971; DiMaggio, 1995; Locke \& Golden-Biddle, 1997; Sutton \& Staw, 1995; Weick, 1995).

It is misleading to think that context matters only for the so-called qualitative researchers. All researchers operate within certain contexts, whether they reflect on it or not. Evocative contexts serve to arouse curiosity among both quantitative and qualitative researchers. However, these researchers typically deal with contexts in very different ways. When collecting data, quantitative researchers aim to control the settings, and to isolate and manipulate variables, aiming to produce causal inferences. While the best quantitative researchers contextualize their findings, most assume their results are generalisable across times and places. Conversely, being aware of the specificity of contexts, many qualitative researchers, particularly from the global South, tend to assume that their findings apply only to their unique contexts. However, by identifying and theorizing the factors and dynamics in their context, they can also generalize via extrapolation, comparison of differences and similarities, and delineation of the boundary conditions. In other words, despite appearances and typical research practices, good practice for any research qualitative or quantitative - is to reflect throughout the research time horizon on the cultural, social, temporal, and material aspects that permeate and enable or restrain a particular observation as well as the production of knowledge and its boundaries.
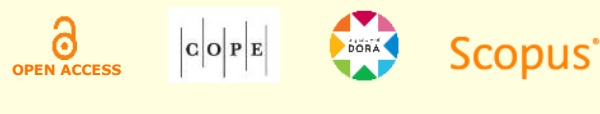
Maribel and Thaysa: Considering the relevance of context for qualitative researchers, how can it be used in favor of producing good theory?

Güliz: As Price, Arnould, and Moisio (2006) note, contexts offer texture and veracity for theoretical stories, but they do not substitute for theories. These authors comment on the dangers of focusing on or "overabsorption by contexts" (Price, Arnould, \& Moisio, 2006, p. 108), as well as review how contexts have been used to build theory in extant literature. As their review also indicates, contexts help us theorize by inviting comparison. A well-chosen context reveals some difference - from what our theories and literature have accounted for thus far - from so-called conventional wisdom. Attempts to explain such a difference can potentially yield a new theorization or an extension or modification of existing conceptualizations. It is important that we do not lose ourselves in the context and treat is as something so unique that it cannot be compared with anything else. On the contrary, by comparing our observations in our context to analogous or homologous ones in other contexts in the literature, as well as relevant theoretical accounts, we can uncover new understandings.

Researchers develop theory based on prior theory, in dialogue with prior theories. The role of context is to provide a phenomenon, an event, a practice, or an occurence to be interpreted and understood through conceptual lenses. The eye trained in the literature (that is, theory) notices something interesting in some context. Alternatively, what a scholar sees in a context depends on her theoretical background or her favorite theory. That is, what we notice and don't notice tend to depend on our own theoretical focus. Hence, the link between context-theory is paramount with respect to both detecting a subject worth investigating as well as accounting for the findings.

The challenge is to locate the best context to spawn novel and interesting insights. A related challenge is to realize that a compelling, richly described context, by itself, is not enough to produce an understanding beyond mere description. As researchers, our endeavor consists of going beyond conventional explanations/understandings in the literature, sometimes by subverting common sense ideas, offering relationships and explanations that may not be discernable at first look, but are built by the researcher's ingenuity, theoretical depth, and analytical capacity. On the one hand, a given context is chosen if it is conducive to understanding a certain phenomenon and/or demonstrating a proposed theoretical relationship. On the other hand, the researcher needs to skillfully and insightfully weave connections between the observations (and smells, sounds, textures) offered by the context and the abstract ideas that she develops, in dialogue with the literature, so that she can offer a new contribution.

Maribel and Thaysa: Given the importance of context, should we highlight it as an integral part of our theory?

Güliz: Context is not a part of our theory; however, it is an integral part of the process of building theory. Context is part of the scholars' theory-building toolbox, akin to our methodological and theoretical toolboxes. Contexts give us boundaries including how, when, where, and under what conditions our theories apply. Contexts show us unexplained differences. Thus, context is germane for us to generate a framework to show how, when, and why the theorization is not

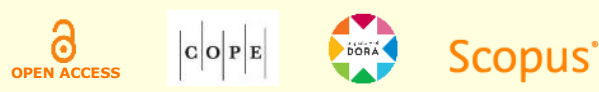


restricted to the specific context in which it was generated. Good qualitative research is bound to seek theoretical generalizability or extrapolation, evidencing new constructs and their complex interactions in social life, which can also occur in other spatio-temporal conditions.

Let me give a concrete example related to my experiences interacting with Brazilian researchers. When they present their projects, Brazilian researchers usually begin with In Brazil... or the Brazilian popular classes. This assumption of and emphasis on singularity from the start, limits the potential broader contributions and generalizibility of their findings. I've studied and worked in the USA for ten years and no one there starts their presentation with an assertion such as in the United States..., the American women... It is always the women, the middle class, etc. What a Brazilian scholar finds about Brazilian popular classes can well be extrapolated to other social groups in other socio-cultural contexts, even if the phenomenon might not be the same at the manifest level. That is, generalization or extrapolation may require analogical thinking and abstraction. For example, based on the voluntarily-covered urban-educated women in Turkey, my co-author and I can generalize our insights about stigmatization and destigmatization, not to other covered Islamic women, but to other stigmatized groups of people and dynamics of destigmatization.

Maribel and Thaysa: What is the problem with this excessive emphasis on Brazilian peculiarities?

Güliz: Why do we have to limit our thinking so much? Why do we have to start with the assumption that some practice, activity, process, event, form, interaction, relationship, etc., that we see in Brazil can only be observed in Brazil and only be explained by Brazilian characteristics? Doesn't this assumption amount to a view that (social) theory cannot be universal but should be context-specific? Generally, Brazilian researchers only describe what is happening in their unique context referring to Brazilian features, dynamics and elements. I live in Turkey and it is the same with many academics in Turkey. Of course, there are specificities about each place, contexts are unique. However, such a priori assumptions end up offering barriers to generalization and extrapolation, as well as contribution and impact, and thus internationalization of Brazilian research. If you assume that what you will find will apply only to Brazil, you will interpret what you observe as a Brazilian feature. This gives rise to the second assumption, which is that you cannot contrast and compare what happens here with any other context. Third, such locating gives the impression that all features and elements in Brazil are the same across the country and it peoples. This is basically essentialization - generalizing certain features and practices of certain peoples in certain settings within Brazil to all peoples, occasions, and places in Brazil. Do all Brazilians do X? Are there no divergences across the different regions of the country, or across different social classes? Essentializing the nation-culture serves only to caricaturize or stereotype certain features and factors and ignore underlying socio-political-cultural factors. Which, by the way, is what the outsiders and the colonizers tended to do throughout history while representing the Other (Said, 1978).

Speaking of the Other (Said, 1978), there is the matter of living in the periphery. Why do you have to assume that you can only dialogue with Brazilian colleagues, speak back to only Brazilian research/literature? Aren't there contributions, extrapolations, implications for research published in international journals? Can't Brazilian scholars say something interesting and have
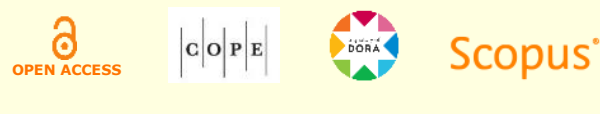
an impact on the work done by in the global North? I would argue that Brazilian, Turkish, or Egyptian researchers can and should engage in a dialogue with the international community of scholars for wider contribution and impact. Doing research in the (semi)periphery poses a challenge: for whom are we producing knowledge? For solely Brazilians? For the Center, the global North? Or for the world - given the prominence of the English language? The answer to this question should be deliberated and given by the individual researcher rather than taken for granted to be solely for the Brazilians. As a researcher, you need to respect your own pace of work and what you want. It is fine to want to have a voice just in the Brazilian academic community as long as this is a decision you make based on what kind of voice you want to have and based on your work rather than your assumptions. Even so, one must have the concern of how to contribute to theorizing starting from a specific context. We, researchers, should be last ones to put limits to the scope of the impact of our work.

Maribel and Thaysa: We often emphasize the specificities to present our context to an audience that does not know Brazil. Instead of creating curiosity, your arguments suggest that this strategy distances Brazilian researchers from international readers.

Güliz: Not instead of. A thick and palpable description of the context can create curiosity and invite engagement among an unfamiliar audience. But this is the beginning of being heard. What you do with and within that context, what new learning you provide is what ultimately will make them remember your voice. You need to show what your context and what you produce using your context brings to the international table of scholarship. Otherwise, your work runs the risk of being read as some interesting story from Brazil, just like a BBC or a National Geographic documentary.

Maribel and Thaysa: Context can help us to theorize and to convince our audience about the novelty of our findings. But, how can we demonstrate this with the rhetorical construction of our articles?

Güliz: We have to explain our context in terms of why it is interesting and fertile to study for the given research purpose and question. We need to link the context to our theorization. First of all, define the phenomenon you want to study and/or the conceptual issue you want to address. Whether you begin with the abstract or the concrete, connecting the two will enhance comprehension and interest. In that process, it is best to make your assumptions explicit. Keep three things in mind: (1) think strategically about the best way to represent your context and story to a particular audience, (2) elicit audience attention and curiosity, and (3) offer some paths for conversation, making the familiar strange and the strange, familiar. All of these require a mental shift on your part. Hogg and Maclaran (2008) provide a fine review of the rhetorical strategies interpretive consumer researchers use "to convince their audiences of the soundness of their theory-building and knowledge generation from their data set" (p. 130). Drawing on GoldenBiddle and Locke (1993), they discuss how researchers tackle the dimensions of authenticity, plausibility and criticality to persuade their readers of the value of their work. I think researchers can use their context to provoke recognition and examination of differences and similarities and boundary conditions, and thus as a means to tackle these dimensions.

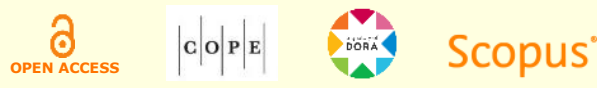


Maribel and Thaysa: What are the challenges to adjust the rhetoric according to an international audience?

Güliz: When we write we tend to think of our audience as people we know, the scholars we interact with in our daily lives. Unless you interact with your international audience often, this is, by definition, not the case for an international audience. They do not know your context and taken-for-granteds and you do not know the audience's cultural references and taken-for-granteds. Of course, there are layers in this regard. Since we want to speak to that audience, the onus is on us to tackle this issue - with the way we write as well as in the way we, as authors and/or as reviewers, inform and coach the journal during the review process. Before writing for a target journal, you need to identify the journal's mission, its readers, and its editorial team and their objectives, and tailor your work to that editorship and readership. Given the blind review process, we do not know who the reviewers are and they do not know who we, the authors are. Despite the absence of familiarity with the reviewers and editors (unlike the peers we interact in our daily lives), we can approximate familiarity by reflecting on their papers - papers of the authors we cite often and/or who work on similar issues. Moreover, and more importantly, we need to be familiar with the debates in both the field and in the specific journal.

Maribel and Thaysa: How do you make these editors and journals familiar?

Güliz: Read their editorials. Go to conferences and talk with editors. Ask about their areas of interest and objectives for the journal. Learn how they think and what their assumptions and priorities are. Have them hear your interests and issues? Going to a conference is not enough. If you are invisible, better not go. If you go, make a difference. Interact with editors and other researchers who have interests similar to yours. Speak your mind and inform the editor or the international colleague of your context and your voice. Participate in discussions. Present your work and listen to and hear the feedback! This is another good way to fine tune your rhetoric. Spend some time at a global North university and discuss your research and their research with your colleagues there. And again, take note of the recent conversations at conferences and in your target journals.

Maribel and Thaysa: We would like to return to the mental shift notion you mentioned. What do you mean by mental shift when discussing the matter of convincing the audience of the relevance of your context and the value of your work?

Güliz: When we sit down to write, we tend to write for ourselves. Some things are implicit or obvious for us, so, we don't unpack them. But, how about the reader? What is obvious and implicit for the reader and what is not? As writers, we have to change our perspective and think from the audience's perspective - create a mental shift in ourselves. For pragmatic purposes, the initial audience includes the reviewers, editor and associate (or area) editors. In order to practice such a mental shift, it helps if we read with the purpose of writing. We need to read: (1) to become familiar with and develop "sensitizing concepts" (Blumer, 1954, p. 7) and/or potentially relevant theoretical frameworks as well as analytic perspectives; (2) to figure out the debates in the field and in the journal; and (3) to figure out how to position our work and frame conceptual issues,
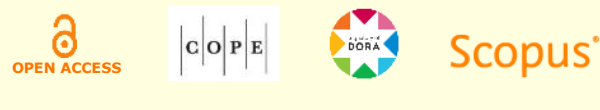
how to represent findings and conclusions so that data and theory cohere, so that the front and back ends of our paper cohere.

Another mental shift you (especially the younger colleagues) need to achive is to approach the literature as something to use to construct your own voice rather than allow the literature to subjugate your voice. Don't let the literature overpower you with conventional concepts and models which might lead you to reproduce already existing knowledge. Instead, interrogate the literature and use the concepts and models in the extant literature to develop your own perspective and conceptualization, in a novel way.

Finally, the mental shift required when we write for international readership is more extreme than when we write for a national one. An incidence, practice, phenomenon, or context that is foreign to them requires a more demanding translation process. You will need to elaborate comparisons, analogies, and metaphors that help to connect your data, phenomenon, and context with your audience.

Maribel and Thaysa: Can you give a concrete example of how to do this?

Güliz: Let's analyse the veiled fashions paper (Sandikci \& Ger, 2010). This work investigates the processes of stigmatization and destigmatization. Our introduction begins with the following provocation:

\begin{abstract}
We are unlikely to encounter Star Trek fans dressed as Trekkies at a business meeting. However, some deviant practices that were once marginal and stigmatized can, over time, become fashionable and ordinary consumption choices. Consider, for example, wearing blue jeans and getting tattoos. We no longer associate jeans with hoodlum motorcycle gangs (Davis, 1989) and tattoos with intimidating exconvicts (DeMello, 2000). Each of these products, once attractive only for a particular group of consumers, now appeal, in a variety of configurations, to the general public (p. 15).
\end{abstract}

The way we mention Trekkies implies that we do not intend to contribute to Kozinets' (2001) paper on Star Trek's culture of consumption. Instead, this is a rhetorical strategy to get the audience's attention - as readers are likely to be familiar with Star Trek and Trekkies, and since interpretive consumer researchers are likely to have read Kozinets' paper. We translate the deviant behavior, which in our case is the Islamic veil in modern urban Turkey, in terms that the audience knows. From the very beginning of the paper, the audience is warned not to be carried away by the Turkish context where the research was done. At the end of the first paragraph, we extend this warning bringing common sense examples beyond Star Trek fans, like tattoos and blue jeans. Therefore, we provide a foundation for the generalizability potential of our findings. The following phrase continues the process of presenting the relevance of our research: "From the consumer's point of view, getting tattoos, wearing jeans, and dressing as a Trekkie, unlike being of a particular ethnicity, are practices s/he volitionally chooses to engage in or not" (Sandikci \& Ger, 2010, p. 15). Note that jeans and tattoos are well known; so, despite the fact that our context is covered women in Turkey, the article deals with the universal phenomenon of volitionally chosen stigmatized practices. From there, the second paragraph begins laying down the positioning of the paper and the room for further contributions: "Despite its' prevalence and

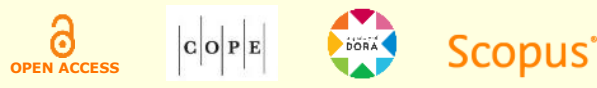


relevance, consumer researchers' interest in stigma remains scant and focuses mostly on stigma management" (p. 15). Thus, we state that the stigma literature is within and against which we position our work.

Maribel and Thaysa: Is it important to formulate research questions that go beyond the context?

Güliz: Yes! Let's continue exemplifying from the veiled fashions paper. The research questions on the second page are:

\begin{abstract}
How and why does a stigmatized practice become a consumption choice in the first place? What are the mechanisms underlying the transformation in the stigma status of this practice? What roles do consumers, the market, and other individual and institutional participants play in adoption and transformation processes? And, what are the personal, societal, and theoretical ramifications of these processes? (Sandikci $\&$ Ger, 2010, p. 16).
\end{abstract}

The research questions are context independent: they refer to any stigmatized practice becoming a choice. They indicate the new learning we promise to provide - the contribution we will make. These questions focus on theoretical ramifications, beyond any contextual characteristics.

Maribel and Thaysa: In Karababa and Ger (2011), in addition to the challenge of the relevance of the geographical context of Turkey, you also had to deal with a historical challenge by discussing a context of the $15^{\text {th }}$ and $16^{\text {th }}$ centuries. What strategy did you use to convince the editor and the reviewers?

Güliz: The article begins with the following sentence: "Pleasure and leisure are two important characteristics of today's consumer culture" (p. 737). We start with a statement that is familiar and acceptable for the audience. This statement also creates a tension with the title, Early Modern Ottoman Coffeehouse Culture and the Formation of the Consumer Subject, that hopefully makes the audience curious. A major challenge while writing this article was to convince the reviewers that we can indeed enrich our understanding about the current consumer culture via a historical context. The first paragraph talks about contemporary cafes, like Starbucks, where pleasurable leisure is enjoyed. The second paragraph states the linkage between the coffeehouse - a site of pleasurable leisure - and the birth of consumer culture as well as the link between the coffeehouse and the public sphere. At the end of the second paragraph we write: "In this study, we address the emergence of this significant site and its consumer in the unexpected Ottoman context rather than in an early modern Western context-the usual home of modernity and modern consumer culture" (p. 737).

By the time we move on to the question of the emergence of the coffeehouse and its subject in the $15^{\text {th }}$ and $16^{\text {th }}$ centuries, we hope that the reader is aware of the connection to the present, a bit curious, and expects to see a paper on leisure and resistance (re: Habermas' notion of the public sphere).

The third paragraph starts with how contemporary studies of consumer culture "portray consumers as subjects who actively negotiate and transform market-mediated meanings to define 
and express their identities and social relations" (p. 738). It moves on to why research is needed on the formation of such a consumer subject; thus, linking the present to the past. Then the research purpose and the conventional view to be interrogated are specified:

Our goal is to (re)examine the active consumer, who has usually been assumed to be the product of twentieth-century capitalism. By going back to an early modern period, we aim to explain how and under what conditions an active consumer subject was formed (p.738).

By this point, hopefully the reader is willing to consider the suitability of the historical context. As you see both of these introductions entail rhetorics and logic in the attempt to convince the reader of the relevance of the context and of potential generalizability from that context - while also positioning the study.

Maribel and Thaysa: Your point is that when presenting an unfamiliar context to a certain audience it's fundamental to engage in a translation process, whether geographic, cultural or temporal. What are the main barriers to succeeding in that task?

Güliz: There are many different types of barriers, including language, cultural, political and economic ones. Take language, a first and foremost barrier. We, for whom English is a second or third language, cannot always communicate our thoughts and arguments clearly in English. It is essential that the researcher improves his/her fluency in English. Think in English, do not just translate - translations do not work. Use academic editing services to help you communicate your ideas accurately. Some journals suggest experienced editing service providers, familiar with the journal's language. This service is used even by native speakers. Moreover, most native Englishspeaking book writers use editors to be able to better communicate with their target audience.

Writing style is another barrier. For example, French write very differently than Anglo-Saxon English speakers. One path to improve our writing in English is to think of the writing process both as a way to develop and crystallize our own thinking and as a way to build an argument to convince a particular audience (or a story to be told to an audience). The writing process goes through three stages: writing as thinking about the data, writing as analysis, and writing as theorizing. The first stage concerns identification of the meanings, understandings, voices and experiences in the data and the structures that shape them. The second is to think through the data-context-theory iteratively to develop analytical ideas and try them out in the process of writing. The last, theorizing, is about thinking with and thinking through data in light of theories. At each stage, we need to ask two questions: (1) is this what I see and think and really want to say? and (2) is this going to be clear and persuasive for my readers?

Cultural barriers pertain to the taken-for-granteds, assumptions, cultural codes, mental shift, and translation issues we already discussed. Economic barriers relate to the costs of using editing services and traveling to conferences and academic institutions abroad. Political issues entail to what extent a scholar wants to be part of a particular international scientific community belonging versus resistance. 
Maribel and Thaysa: Sometimes rhetoric and the way journals structure discussion vary from journal to journal?

Güliz: Yes, and that's another reason to get familiar with the journal, particularly, its recent issues, before you start to write your final manuscript. How the different sections of a manuscript are structured and formed, the rhetorics, the styles of argumentation and story telling, can all vary. The variations are not only across journals but also within journals over time; hence, the suggestion to peruse recent issues.

Maribel and Thaysa: Are there any general suggestions for writing despite such changes and variations?

Güliz: Yes. The most important parts of an article are the first few pages and the final few ones. If the author manages to make the reader curious and stimulated during the first few pages, the reader will read the piece. And, if in the end, s/he can make the reader feel and think that s/he has learned something new, great; if the reader is then inspired and stimulated so that s/he can come up with ideas for her own research, fantastic! The beginning of the article, therefore, should arouse curiosity and tension while the final part should resolve it. The introduction has the main function of answering the following questions: why this research, why is this research important, why this approach, and why this context. Answering the why this research question starts with the clarification of what we know and do not know (or don't understand or misunderstand or partially understand). This is obviously literature-based and in dialogue with theory. You can begin your paper either based on a theoretical issue or an observation, which you connect to an unknown in the literature and/or a theoretical issue. Some examples are: Here is a theoretical problem (problematization of conventional conceptionalizations), or Here is a surprising/puzzling phenomenon, an anomaly (deviation from the common rule/type/arrangement/form based on your observations) or Here is a paradox. Once the problem, puzzle, the paradox, and the unknown or the misunderstood or the partially understood are spelled out, you go to The purpose of my research is ... phase. You need to persuade the reader that your work is novel and different than previous work, and that difference promises a new and valuable insight. Ultimately, you need to characterize conventional wisdom and then challenge, re-frame, or extend it - different manners of advancing knowledge. In doing so, positioning your work based on a rationale is much more convincing than positioning based on a lack. It is more convincing to give the reader reasons why it is necessary to address this topic/issue/research question than pointing out that $\mathrm{X}$ has not been studied before.

Let's see how my co-author Türe and I tackled the above (as well as the other challenges we discussed so far) while writing our paper titled "Continuity through change: Navigating temporalities through heirloom rejuvenation" (Türe \& Ger, 2016). While doing her fieldwork for her doctoral thesis on disposing, Meltem noticed (prepared mind!) that some cherished items are neither disposed of nor treated anything like the heirlooms depicted in the consumer research literature. Instead, they are reused after some transformation. The first paragraph states what the conventional wisdom is and why we challenge it:

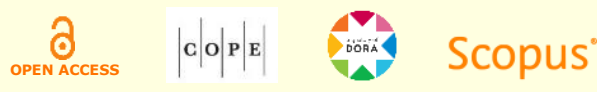


Consumer researchers focus on heirlooms-materializations of family meanings and traditions-as identity anchors ... scholars have stressed the importance of heirlooms in providing consumers with a sense of stability and continuity. ... Alternatively, we consider the iterative and interactive relation between change and continuity (Giddens, 1990; Miles, 2001; Schatzki, 2002) and explore heirlooms' capacity for enacting change in addition to being sources of stability (p.1).

Thus, from the perspective of social theory on change and continuity, we interrogate the status of heirlooms as objects of family identity and stability. In other words, we hint that we will be problematizing the theorization of heirlooms. In the second paragraph we provide some examples from North American markets and popular culture so that the reader can connect the Turkish context to things they are familiar with. We end the second paragraph with our research question: "we focus on heirloom consumption practices that are more dynamic and transformative than previously found. We ask if, how, and when heirlooms are transformed” (p. 4).

While the third paragraph poses conceptual questions, the fourth paragraph argues why urban Turkey is a fertile context to address our research question. The rest of the introduction section lays out the three theoretical perspectives we draw from - our theoretical toolbox. Then the socalled theory or literature review section, titled Consumption of heirlooms, reviews and problematizes that literature. The next section, titled The site and its imaginaries, lays out the context in its connection to our theoretical perspective. And so on.

Similar to providing the rationale for your study, later in the paper, it is good practice to provide (implicity or explicity, depending on the journal's conventions of writing) the rationale for your research method and context. The reader should get the idea that your approach allows a rigorous investigation of your research objective. Whether you use tables or text or figures, you must make your methodology transparent. While writing the findings, make sure that you have used all the different kinds of data you claim to have amassed. Finishing the article is also important. The reader must leave the paper feeling and thinking that $\mathrm{s} /$ he has learned something $\mathrm{s} /$ he did not know before. Lastly, any individual article need not represent the totality of what your study uncovered. Readers, reviewers, and editors of journals published in the English language expect that you make one compelling point, not many points.

Maribel and Thaysa: How to overcome cultural barriers?

Güliz: As we've discussed, the main challenge is how to explain and theorize one particular consumer culture or market to someone knowledgeable about another. To overcome this challenge, it is necessary to explain your case in terms of similarities and differences rather than only differences. Besides that, the researcher should seek to explain the particular phenomenonin-context while extending/contributing to theory in order to generalize or extrapolate to other contexts. As professors, we actually learn how to do it for one audience - our students, using our teaching techniques. Think about how you capture the attention of your students, different in terms of generation and cultural backgrounds. How do you make them understand your point? Doesn't teaching also entail a mental shift - considering the student's perspective? Writing an international article bears a similar if more extreme challenge.

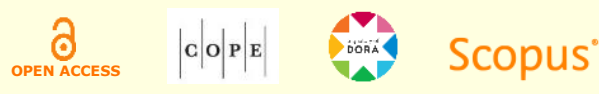


Maribel and Thaysa: How should the researcher from the global South deal with her context in the international dialogue to avoid being perceived as a peripheral, tangential, or as the exotic Other?

Güliz: Whether in explaining your specific context or phenomenon, one approach is to represent clearly the core of it and its dimensions and dynamics that pertain to your conceptualization and analysis. The representation should go beyond description; instead you should relate your context to your research questions, relevant concepts and theoretical toolbox, and analytical approach. Another tactic is to find similar cases to compare with in order to convince your international audience of the relevance and importance of your context. In addition, we must be careful to avoid overabsorption in our context which can blind us to potential generalizability. Too much focus on uniqueness and exceptionality can prevent seeing universality. We cannot forget that highlighting specificity and difference reinforces how the Center thinks about the contexts from the South - the Other. This takes us back to the problem of essentializing we discussed earlier. Instead of essentializing, we need to examine the similarities and differences in our context and others already known to the global North analytically and theoretically.

The outsider position of scholars from the Global South has its advantages. It offers the possibility of proposing innovative dialogues that can transform the manner in which the international scientific community perceives phenomena and issues, and produces knowledge. A researcher is a sociocultural product and also a producer of culture, or the social reality of North-South relations. Global south researchers can make a global contribution by providing approaches, theorizations, and solutions that the global North researchers fail to see or to consider or to critically reflect upon. I am talking about a sociopolitical researcher reflexivity that goes beyond methodological issues. Perhaps it is less painful to critically reflect about certain social issues looking at them from the South. Perhaps the global South will endow us an innovative perspective if we have the courage to tell our own stories. Or, as we reflect critically, we will build our courage. With such courage and using her context, the researcher can go beyond application and re-affirmation of theorizations and models of the global North - and thus have a critical and significant voice in the international field.

Maribel and Thaysa: You've recently published a curatorial paper in JCR (Ger, 2018) on intersectionality that pertains to such sociopolitical issues. Can you comment on this?

Güliz: As Arundati Roy has said, focusing on a person (consumer, informant) hides the system behind it. We need to better understand systemic dynamics, that is the structural, institutional and political factors, all of which have a momentous bearing on consumer practices and social issues. One way of doing this is through intersectionality, which is an approach to studying power differentials by examining the relationships among subjectivity, knowledge, power, resistance, and social structures. Intersectionality requires a both/and thinking, connecting the structural and the experiential/personal as well as the material and the discursive. Intersectionality asks for a critical reflexivity as well as an interrogation of the privileged positions through the kinds of research questions we ask, the analyses we do, and the outcomes we seek in research. Most pertinent to our discussion here are: (1) the role of critical reflexivity and (2) a critical, analytical,
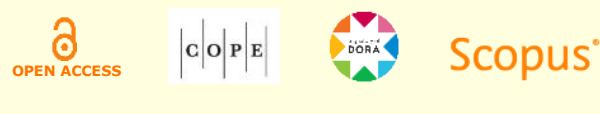
and conceptual examination of not just the context but also the context of the context (Askegaard $\&$ Linnet, 2011). We must contextualize the context in its historicity as well as the macro factors and structures.

Maribel and Thaysa: What final advice do you have for the researchers who decide to internationalize their work?

Güliz: You have to know your stuff and be brave, persistent, and patient enough to engage in a dialogue without giving up. Rather than be discouraged by negative reception, criticism, or even rejection, you have to give convincing responses, arguments, and rationales to the readers, reviewers, and editors. First, you need to listen to your audience and listen between-the lines. You need to learn what your audience is thinking, what their assumptions and conventions are. Yes, you need to address their concerns, but not necessarily on their terms. If you can invoke persuasive rationales for your methodological, contextual, and theoretical decisions and approaches, they will listen. Several years ago, my colleagues submitted a paper based on the fieldwork they conducted in Turkey for a top-tier journal. They received a desk rejection, i.e. the article would not even be sent out to the reviewers. The editor questioned the relevance of and generalizability from a specific site, a city in Turkey. We read the letter carefully, sleeping on it for a week or two, and decided to write a response. We discussed at length what the response should entail and how it should be composed. My colleagues wrote a two-page letter to the editor arguing that a city in the USA is also a specific site. If a paper that uses a sample and a site/context form a particular US city can be published, so can one from any city in the world, as long as that city is appropriate for the research questions and the proposed theorization. Similarly, if researchers can generalize or extrapolate from their USA sample and context to other theoretically and phenomenologically relevant situations so can they from a Turkish sample. (There were of course other issues and arguments as to the importance of the work as well). The point is, if you think through the epistemological, ontological, methodological and theoretical issues that surround your research questions and approach, and form your arguments and rationales accordingly, you have a good chance to make your voice heard. In my colleagues' case, the day after they e-mailed their refutation of the desk-reject decision, the editor responded by apologizing and sending the article to the reviewers. After a round of reviews and revisions, the article was published. So, the authors' voices were heard, the importance and relevance of their work was acknowledged.

Finally, collaborating with other colleagues, not only from the global North, but also from the global South, helps build emotional solidarity, empowerment, and learning from shared experiences and critical reflections. Thus, we can assemble ideas as to how to tackle the challenges of contextualizing without essentializing, generalizing/extrapolating while appreciating specificity, and using the context (and the context of the context!) in conceptualizing and theorizing. 


\section{Concluding Remarks}

The questions and answers presented above were compiled in two workshops held at the COPPEAD Graduate School of Business of the Federal University of Rio de Janeiro in 2017 and 2018. Among other things in those workshops, several critical questions were raised including the following: (a) Does the incentive to produce research for an international audience distract our focus from national problems? (b) Does the theoretical elaboration demanded by international journals divert us from the most fundamental Brazilian problems? (c) Does the emphasis on producing papers in English reduce the opportunities to dialogue with Brazilian peers and to educate students who may not be fluent in that language?

We began with questions that pertain to the challenges of doing research and writing for an international audience and the tradeoffs between a focus on Brazilian problems and Brazilian researchers versus a focus on producing and writing research for an international audience. Instead of closing these issues, Professor Ger's ideas and experiences presented in this interview elicit food for thought that richly enhances our reflexivity as researchers. Her arguments illuminate some important barriers, pertaining to our deeply entrenched cultural perspective. A first assumption commonly held in Brazilian research is that national problems or cultural issues are of no interest to international audiences. Urgent issues in our context such as economic and educational inequality, gender and racial prejudice, violence and corruption, which permeate multiple contemporary realms domestically, are likewise dominant topics in global debates. Brazil also presents itself as a fertile context for investigation of issues related to environmental sustainability, spirituality, the processes of corporate globalization, and acculturation, among many other themes emerging in international literature. The impossibility of reconciling the national and international perspectives and overemphasis on Brazilian singularity, more properly characterized as presumptions than anything else, may reflect Brazilian researchers' insecurities, which, as Professor Ger herself mentions in her lectures, is a characteristic common to most academics around the world. To some extent, more or less, tradeoffs may exist for certain research topics or domains. In any case, however, Brazilian researchers can creatively navigate and generate resolutions as well.

Likewise, the effort to improve our theoretical elaboration should not be seen as a challenge imposed by internationalization. Thinking about and reviewing Brazilian problems in an original way requires that our researchers employ systematic and rigorous knowledge generation wellfounded in clearly presented analysis and conceptualization work in concert with extant theory, regardless of the audience, domestic or international. A backdrop of questioning related to theoretical elaboration is characteristic discussion related to the value of academic knowledge. However, the basic premise into which research invests is the understanding that knowledge and not merely techniques are fundamental input to public deliberation and decision making when dealing with social problems.

Discussions about responsible science and social impact of research in administration are not restricted to Brazil (Guarido, 2018), but increasingly present in different institutions around the world (Tonelli \& Zambaldi, 2018). In this sense, it is important to join forces with researchers from

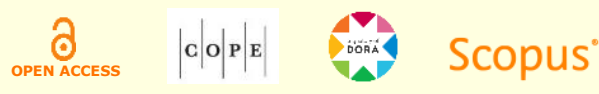


other countries interested in reflecting on the extent to which the academic system has become a closed system unto itself, detached from societal demands and, ultimately becoming less relevant.

Finally, the language barrier is an important issue. A thought-provoking essay on this subject is offered by Alves and Pozzebon (2013) which questions the unreflexive use of English in academic practices. Besides economic barriers created by translation and editing services and access to academic institutions abroad to sustain a permanent dialogue, it is essential to reflect upon the emphasis placed upon producing papers in English, especially when acknowledging that this initiative has become routine current practice among the most important Brazilian journals. As Diniz (2017) and Farias (2017) argue, the main objective to be pursued by any journal is scientific and editorial quality, and publication in English is just one of the requirements and strategies for achieving internationalization.

This discussion requires both/and thinking rather than a mindset of instead of/or. An important alternative are the multi-language journals (Alves \& Pozzebon, 2013), that provide the evaluation and publication of manuscripts in different languages. Another example of this both/and attitude would be acknowledging and even insisting upon the importance of Brazilian journal's editorial policies to publish both Portuguese and English versions of submissions. Thus, instead of reducing the dialogue, we are effectively expanding the possibility of increasing the readership of the research produced in Brazil. Some journals published in Brazil have embraced the idea of proposing that the review process and publication be completed in both languages. However, the labor and/or additional financial burdens that fall on the article authors' and their institutions, thus potentially further narrowing the possibilities of publication of research from academia and educational institutions with more limited financial resources.

The ideas raised by Professor Ger lead us to think more seriously about who or what is being discussed and researched and for whom we are creating knowledge. Regardless of the language adopted by the journals, content published by the Brazilian journals is poorly cited by Brazilian researchers (Machado-da-Silva, Guarido, Rossoni, \& Graeff, 2008). In other words, not only international colleagues, but even our own Brazilian peers read/cite very little of the rich wealth of research extant and increasing continuously in both quality and quantity from Brazil. In this sense, we also need to discuss and contemplate strategies to overcome our peers' prejudices and convince the domestic audience of the value of our research.

These questions continue to be rigorously and productively debated within the Brazilian Academy. Arguably, carrying on the debate serves to improve and enrich research conducted within Brazil and its value as a significant perspective reflecting on and relevant to global problems. 


\section{Interviewee}

Güliz Ger is a Professor of Marketing and Director of the Center for Research in Transitional Societies at Bilkent University in Ankara, Turkey. Recently, she is also a part-time visiting professor at the University of Southern Denmark and SKEMA, France. Her research has been published in high impact international journals, such as the Journal of Consumer Research, California Management Review, and Consumption, Markets and Culture, among many others. In this interview, Professor Ger discussed the challenges and opportunities of theorizing qualitative research based in specific contexts. The conversation also addresses challenges of knowledge production from the Global south perspective. Guliz Ger's work inspires Global south researchers by offering concrete examples on how to theorize from contexts outside the commonly used prism of Eurocentric geography. Her experience as a visiting professor in numerous universities around the world and service at journal editorial boards, including the Journal of Consumer Research, where she served as Associate Editor, provided the background for this interview produced by Maribel Suarez and Thaysa Nascimento. Her core ideas about theorizing from different contexts were compiled and presented in two different workshops held at the COPPEAD Graduate School of Business of the Federal University of Rio de Janeiro in 2017 and 2018.

\section{References}

Alves, M. A., \& Pozzebon, M. (2013). How to resist linguistic domination and promote knowledge diversity? RAERevista de Administração de Empresas, 53(6), 629-633. https://doi.org/10.1590/S0034-759020130610

Alvesson, M., \& Sandberg, J. (2011). Generating research questions through problematization. Academy of Management Review, 36(2), 247-271. https://doi.org/10.5465/amr.2011.59330882

Askegaard, S., \& Linnet, J. T. (2011). Towards an epistemology of consumer culture theory: Phenomenology and the context of context. Marketing Theory, 11(4), 381-404. https://doi.org/10.1177/1470593111418796

Blumer, H. (1954). What is wrong with social theory? American Sociological Review, 19(1), 3-10. https://doi.org/10.2307/2088165

Davis, M. S. (1971). That's interesting! Towards a phenomenology of sociology and a sociology of phenomenology. Philosophy of the Social Sciences, 1(2), 309-344. https://doi.org/10.1177/004839317100100211

Davis, F. (1989). Of maids uniforms and blue jeans: The drama of status ambivalences in clothing and fashion. Qualitative Sociology, 12(4), 337-355. https://doi.org/10.1007/BF00989396

DeMello, M. (2000). Bodies of inscription: A cultural history of the modern tattoo community. Durkam, NC: Duke University Press.

DiMaggio, P. (1995). Comments on what theory is not. Administrative Science Quarterly, 40(3), $391-397$. https://doi.org/10.2307/2393790

Diniz, E. H. (2017). Periódicos brasileiros da área de Administração no contexto de internacionalização da produção científica. Revista de Administração de Empresas, 57(4), 357-364. https://dx.doi.org/10.1590/s0034759020170406

Farias, S. A. (2017). Internacionalização dos periódicos brasileiros. Revista de Administração de Empresas, 57(4), 401404. https://dx.doi.org/10.1590/s0034-759020170409

Ger, G. (2018, Spring). Intersectional structuring of consumption. Retrieved from https://academic.oup.com/jcr/pages/ger_introduction 
Giddens, A. (1990). The consequences of modernity. Cambridge, UK: Polity.

Golden-Biddle, K., \& Locke, K. (1993). Appealing work: An investigation of how ethnographic texts convince. Organization Science, 4(4), 595-616. https://doi.org/10.1287/orsc.4.4.595

Guarido, E. R., Filho. (2018). Desigualdade social, responsabilidade e responsividade da pesquisa. RAE-Revista de Administração de Empresas, 58(5), 511-516. http://dx.doi.org/10.1590/S0034-759020180507

Hogg, M. K., \& Maclaran, P. (2008). Rhetorical issues in writing interpretivist consumer research. Qualitative Market Research: An International Journal, 11(2), 130-146. https://doi.org/10.1108/13522750810864404

Karababa, E., \& Ger, G. (2011). Early modern ottoman coffeehouse culture and the formation of the consumer subject. Journal of Consumer Research, 37(5), 737-60. https://doi.org/10.1086/656422

Kozinets, R. V. (2001). Utopian enterprise: Articulating the meanings of Star Trek's culture of consumption. Journal of Consumer Research, 28(1), 67-88. https://doi.org/10.1086/321948

Locke, K. D., \& Golden-Biddle, K. (1997). Constructing opportunities for contribution. Academy of Management Journal, 40(5) 1023-1063. https://doi.org/10.5465/256926

Machado-da-Silva, C. L., Guarido, E. R., Filho, Rossoni, L., \& Graeff, J. F. (2008). Periódicos brasileiros de administração: Análise bibliométrica de impacto no triênio 2005- 2007. RAC-Eletrônica, 2(3), 351-373. Retrieved from http://www.anpad.org.br/periodicos/arq_pdf/a_821.pdf

Miles, S. (2001). Social theory in the real world. London, UK: Sage.

Price, L., Arnould, E., \& Moisio, R. (2006). Making contexts matter: Selecting research contexts for theoretical insights. In R. W. Belk (Ed.), Handbook of qualitative research methods in marketing (pp. 106-125). Cheltenham, UK: Edward Elgar.

Sandikci, Ö., \& Ger, G. (2010). Veiling in style: How does a stigmatized practice become fashionable? Journal of Consumer Research, 37(1), 15-36. https://doi.org/10.1086/649910

Schatzki, T. (2002). The site of the social: A philosophical account of the constitution of social life and change. University Park, PA: Pennsylvania State University Press.

Tonelli, M. J., \& Zambaldi, F. (2018). Ciência responsável e impacto social da pesquisa em Administração. RAERevista de Administração de Empresas, 58(3), 215-216. https://doi.org/10.1590/S0034-759020180301

Türe, M., \& Ger, G. (2016). Continuity through change: Navigating temporalities through heirloom rejuvenation. Journal of Consumer Research, 43(1), 1-25. https://doi.org/10.1093/jcr/ucw011

Said, E. (1978). Orientalism. New York, NY: Vintage Books.

Sutton, R. I., \& Staw, B. M. (1995). What theory is not. Administrative Science Quarterly, 40(3), 371-384. https://doi.org/10.2307/2393788

Weick, K. E. (1995). What theory is not, theorizing is. Administrative Science Quarterly, 40(3), 385-390. https://doi.org/10.2307/2393789

\section{Author contributions}

$1^{\text {st }}$ author: project administration (equal), writing-original draft (equal), writing-review and editing (equal).

$2^{\text {nd }}$ author: conceptualization (equal), project administration (equal), writing-original draft (equal), writing-review and editing (equal).

$3^{\text {rd }}$ author: conceptualization (equal), writing-original draft (equal), writing-review and editing (equal).

Scopus 


\section{Authors}

\section{Güliz Ger}

Bilkent University, Faculty of Economics, Administrative and Social Sciences

TR-06800 Bilkent, Ankara, Turkey

gerguliz@gmail.com

(iD) https://orcid.org/0000-0002-7665-046X

\section{Maribel Carvalho Suarez}

Universidade Federal do Rio de Janeiro, Instituto de Pós-Graduação e Pesquisa em Administração Rua Pascoal Lemme, 355, Ilha do Fundão, 21941-972, Rio de Janeiro, RJ, Brazil

maribels@coppead.ufrj.br

(iD) https://orcid.org/0000-0001-9736-5273

\section{Thaysa Costa do Nascimento}

Universidade Federal do Rio de Janeiro, Instituto de Pós-Graduação e Pesquisa em Administração Rua Pascoal Lemme, 355, Ilha do Fundão, 21941-972, Rio de Janeiro, RJ, Brazil thaysa.nascimento@coppead.ufrj.br

(iD) https://orcid.org/0000-0002-5706-6022

Peer review is responsible for acknowledging an article's potential contribution to the frontiers of scholarly knowledge on business or public administration. The authors are the ultimate responsible for the consistency of the theoretical references, the accurate report of empirical data, the personal perspectives, and the use of copyrighted material. 